\title{
GAMPI
}

\section{Um olhar do design a partir da abordagem do Upcycling}

A look design from the Upcycling approach

SANTOS, Bruna Fischer dos; Bolsista de Iniciação Científica em Design de Produto; UNIVILLE bruna.fischers@gmail.com

CAVALCANTI, Anna Luiza Moraes de Sá; Orientadora, Professora do Depto. Design; UNIVILLE anna.cavalcanti08@gmail.com

\section{Resumo}

Apesar da difusão do conceito de sustentabilidade, ainda há muitas barreiras a serem ultrapassadas, sobretudo, em relação ao reuso dos artefatos e da matéria-prima, sem que a mesma sofra modificações, contribuindo, desta forma para a preservação do meio ambiente. A metodologia utilizada inclui pesquisas bibliográficas, documentais e de campo, sendo alvo de estudos os grupos que praticam o upcycling como empreendimento individual ou como empresa constituída, tecendo uma análise mais profunda sob o olhar do Design. A pesquisa busca responder questões como: qual o destino final de resíduos considerados "inutilizáveis" e como reaproveitá-los de forma criativa e sem modificá-los quimicamente.

Palavras chave: upcycling; sustentabilidade; design.

\begin{abstract}
Despite the spread of the concept of sustainability, there are still many barriers to be overcome, particularly in relation to the reuse of artifacts and the raw material without which it suffers modifications, thus contributing to the preservation of the environment. The methodology includes bibliographic research, documentary and field studies being targeted by groups who do upcycling as individual enterprise or as established enterprises weaving a closer look under the gaze of Design. The research seeks to answer questions such as: what is the final destination of wastes characterized as "unusable" and repackage them as creatively and without modifying them chemically.
\end{abstract}

Keywords: upcycling; sustainability; design. 


\section{GAMPI
plural ${ }^{15}$}

\section{Introdução}

Este artigo foi elaborado com o objetivo de apresentar a pesquisa de PIBIC em andamento sobre os arranjos produtivos na região de Joinville com o foco no upcycling, procurando entender como se organizam e quais são os resultados obtidos em relação à reutilização da matéria-prima para a geração de um novo produto.

Segundo Lavosier "na natureza nada se cria, tudo se transforma", porém no mundo material, o termo upcycling surgiu como necessidade e tornou-se uma tendência principalmente no âmbito do design - com a reutilização de materiais para criação de novos artefatos com uma abordagem criativa e mais consciente, pois os materiais utilizados não precisam sofrer modificações para se tornarem um novo produto, sendo um processo mais sustentável, que também prolonga a vida útil dos objetos.

Para entender um pouco mais sobre este processo, se faz necessário esclarecer a diferença entre upcycling e reciclagem. Segundo Naime (2005, p. 98), a reciclagem "consiste no reprocessamento, incluindo um ou mais processos industriais do resíduo sólido gerado, que serve de matéria-prima para o novo processo industrial", ou seja, tal prática está baseada no recolhimento, separação e processamento de materiais descartados para a criação de um novo ciclo com este material, através de transformações químicas.

O upcycling está relacionado ao processo de recuperação de materiais que já chegaram ao fim da vida útil (aquela a que foram propostos a executar). Tais materiais são transformados e reaproveitados de maneira que, sem perder a forma original, ainda assim, se tornem produtos de qualidade e valor agregado (McDONOUGH; BRAUNGART, 2002). É uma prática que estimula a criatividade e é ambientalmente correto, pois além de educar a sociedade a ter pensamentos mais sustentáveis, muitas vezes resulta em artefatos de grande valor agregado com o reaproveitamento dos resíduos.

\section{O Pensamento Sustentável como Influência na Prática do Upcycling}

De acordo com Buainain (2006, p. 47), o conceito de sustentabilidade tem "forte conteúdo ambiental e um apelo claro à preservação e à recuperação dos ecossistemas e dos recursos naturais". Muito se debate sobre a sustentabilidade nos dias de hoje. Essa crescente preocupação fez surgir diversas iniciativas a fim de demonstrar sua relevância.

A sustentabilidade está relacionada ao contexto sócio-econômico-ambiental, visto que, qualquer atividade desenvolvida pelo homem causa impacto em seu cotidiano e no ambiente em que está inserido, seja ele negativo, ou não. É importante ressaltar que, para que haja equilíbrio ambiental e desenvolvimento sustentável, as atividades humanas devem ser compatíveis com os ciclos naturais, diminuindo o impacto ambiental.

Assim, iniciativas que adotam a responsabilidade socioambiental vêm demonstrando que os impactos são positivos e promovem uma nova postura de consumo, pois os produtos produzidos são singulares e trazem em sua essência o baixo impacto ambiental e o desafio de prolongar a vida útil de um material que já não seria mais utilizado, dando-lhe um novo ciclo de vida.

\section{As Iniciativas de Upcycling na Região de Joinville}

A pesquisa procurou entender como surgiram estas iniciativas, como se estruturam e desenvolvem suas ações e como a cadeia produtiva está organizada, bem como, se tais produções são artesanais ou já industrializadas. 


\section{GAMPI
plural ${ }^{15}$}

Segundo o SEBRAE, diversos grupos vêm se movimentando para incluir a responsabilidade social em suas práticas produtivas, pois quando tais iniciativas passam a trabalhar desta forma, não só se obtém mais lucro com produtos de valor agregado mais elevado, como a própria empresa ganha mais valor e reconhecimento diante dos consumidores.

Em sua maioria, estrutura-se como empreendimento individual, que se caracteriza por uma iniciativa por conta própria, legalizada como pequeno empresário (gráfico 1).

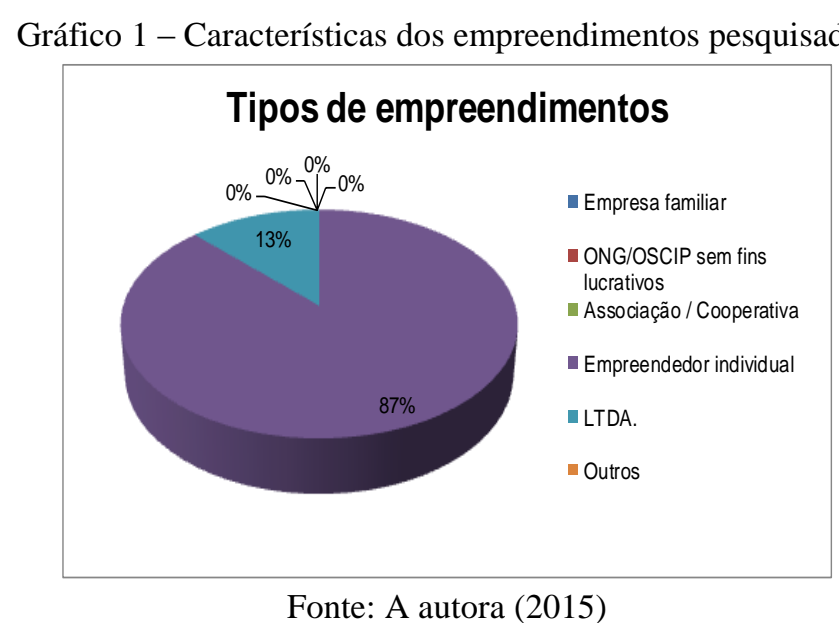

Estes empreendimentos criam condições para o melhor aproveitamento dos resíduos e estão ligados ao desenvolvimento sócio sustentável que, segundo Ferreira Neto (1987, p. 15) "é um conjunto planejado de ações, contemplando as várias dimensões das necessidades vitais de uma população"; devido ao fato de atenderem às necessidades das gerações presentes, sem comprometer a capacidade das gerações futuras de suprirem suas próprias necessidades.

Por meio de estudos bibliográficos e de campo como principais fontes de informação, este artigo apresenta experiências dos empreendedores dos arranjos produtivos locais, que surgiram a partir da necessidade de utilizar os resíduos para gerar um novo ciclo de vida sem ser prejudicial ao meio ambiente.

Assim, foi realizada uma pesquisa de caráter qualitativo, apoiada em um questionário aplicado durante a $7^{\mathrm{a}}$ edição do evento (In)Consciente Coletivo, que representa a cultura contemporânea na região. Em 2015 ocorreu nos dias 11 e 12 de julho, na Casa da Cultura em Joinville e reuniu cerca de 40 expositores, onde artistas, designers, artesãos etc., compartilharam seus trabalhos e produtos com o público.

Dentre os expositores, foram selecionados aqueles com foco no upcycling: DoodWood, BemComum, Ana Gern, Lardic, Rust Miner e Zebra Design \& Estúdio. Por meio de contato com os organizadores do evento, foi possível contatar outros dois expositores de edições passadas: Fuckcars e Esiat Atelier. Todos os empreendedores têm uma ligação muito forte com o design responsável e sustentável. A pesquisa junto aos empreendedores partiu inicialmente de conversas informais e, posteriormente, da aplicação do questionário para conhecer algumas características do trabalho realizado.

Foi possível constatar que a maior preocupação dos empreendedores é propagar a ideia de ressignificação dos materiais associado ao conceito de sustentabilidade na produção dos artefatos. "Ter um olhar diferenciado sobre um material de descarte, não é uma tarefa simples, 


\section{plural $^{\text {GA }}$}

pois, para muitos, o que é considerado lixo, nas mãos das pessoas certas, pode se tornar um artefato exclusivo".

Muitas vezes, a concepção de um objeto por meio de materiais que já chegaram ao fim de sua vida útil prevista, é desafiador, pois é preciso que o designer/artesão saiba selecionar os resíduos com que trabalhará e o tipo de acabamento, para que se torne um artigo de qualidade e com valor percebido para despertar o interesse dos consumidores.

A figura 1 apresenta o cuidado com que os designers da DoodWood têm com cada peça confeccionada, cuja madeira é tratada e recebe acabamento manual para preservar sua originalidade.

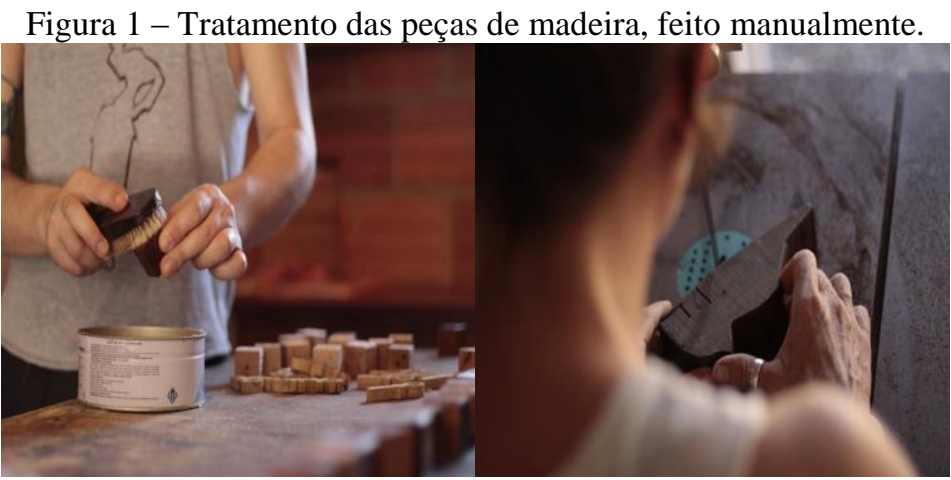

Fonte: Doodwood (2015, web)

Além da produção dos artefatos ser completamente feita a mão, nenhuma peça recebe pintura. A coloração do produto geralmente é crua, com a cor da própria madeira, que sofre variações de acordo com o tipo de cada matéria-prima. Se há alguma peça colorida é justamente porque as madeiras reutilizadas também são adquiridas em demolições de residências. Neste caso, as peças são lixadas para que o excesso de tinta seja retirado, dando um efeito diferenciado ao artefato, como mostra a figura 2.

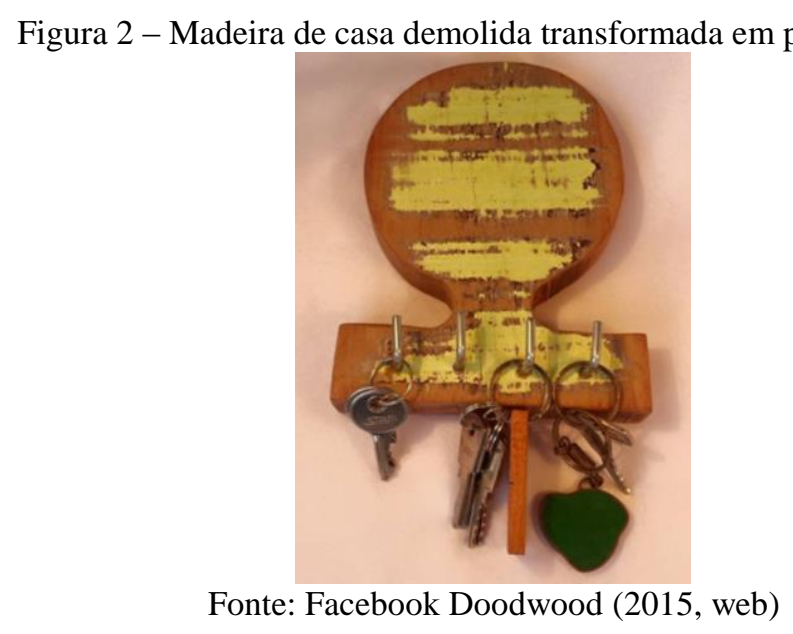

Segundo Rafael da DoodWood, a ressignificação de materiais é um tema que ganhou muita abrangência nos últimos tempos e está cada vez mais forte no dia a dia dos designers e dos consumidores que exigem soluções mais conscientes. Bastante preocupados com o meio 


\section{plural $^{\text {GA }}$}

ambiente e o futuro da sociedade, os entrevistados evidenciam que é preciso muito mais que boas ideias e, a palavra chave é inovação.

Inovação é um conjunto de três fatores bastante pertinentes para quem busca resultados diferentes em seus produtos: criatividade, exploração de possibilidades e ideias, além de pensar em todo o ciclo de vida. Como exemplo, o designer conta que tanto a seleção das madeiras com que trabalha, o tipo de acabamento e até as embalagens que envolvem as peças prontas são pensados minuciosamente. Desta forma, iniciativas regionais vêm buscando cada vez mais meios de inserir a prática do upcycling em suas cadeias produtivas.

As oportunidades de negócio percebidas pelos empreendedores por meio do upcycling nasceram, em sua maioria, antes da concepção do modelo de negócio e da produção de seus artigos. De acordo com os pesquisados, essa preocupação com o meio ambiente já é algo que vem de geração em geração, bem como, a vontade de fazer algo diferente, que realmente impacte na vida das pessoas e as façam pensar no valor agregado dos artefatos.

No entanto, para a equipe da BemComum, o upcycling veio depois. Inicialmente, o foco era disseminar uma nova forma de trabalho e filosofia de vida com o objetivo de fazer com que pessoas descobrissem suas habilidades pessoais e profissionais. De acordo com a equipe: "partindo deste princípio, houve o surgimento do trabalho com materiais sustentáveis, trabalhando através da exclusividade". Ainda, segundo relato da equipe, todos os materiais selecionados são utilizados. O desafio é encontrar formas criativas de reaproveitá-los ao máximo. Muitas vezes, durante o processo produtivo, encontram-se novas finalidades para a matéria-prima.

Dentre os muitos produtos que podem ser criados a partir de um material de descarte, estão acessórios pessoais, artigos de decoração para casa, brinquedos e até bicicletas.

Um exemplo da reutilização dos materiais se dá através de ourelas, fios ou retalhos de tecidos de teste, doados por empresas do ramo têxtil. A iniciativa partiu da empreendedora Ana Gern, que desde criança via sua mãe e avó reutilizando tecidos para customizar ou criar novas peças. Através da parceria com as empresas Döhler e RVB Malhas, a designer cria bolsas, colares, almofadas, jogos americanos entre outros (figura 3 ).

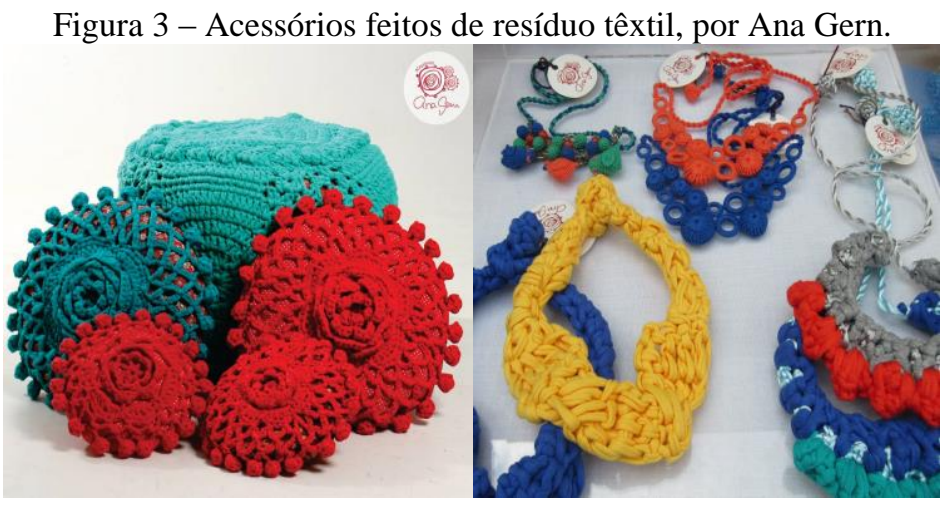

Fonte: Ana Gern (2015, web)

A empresa Lardic é outro empreendimento cujos artefatos são confeccionados reutilizando retalhos de couro que seriam descartados pelo corte irregular, pequenos defeitos na superfície ou ainda, por serem sobras de outras peças já confeccionadas. A matéria-prima reaproveitada é, neste caso, essencialmente o couro. Os demais aviamentos e metais são 


\section{GAMPI plural 15}

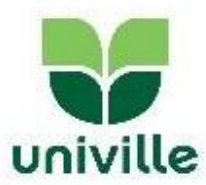

comprados para dar acabamento à peça. Segundo Evandro, responsável pela empresa, os principais benefícios da reutilização do material são: "economia na compra de matéria-prima e valor agregado pelo conceito de sustentabilidade" (figura 4).

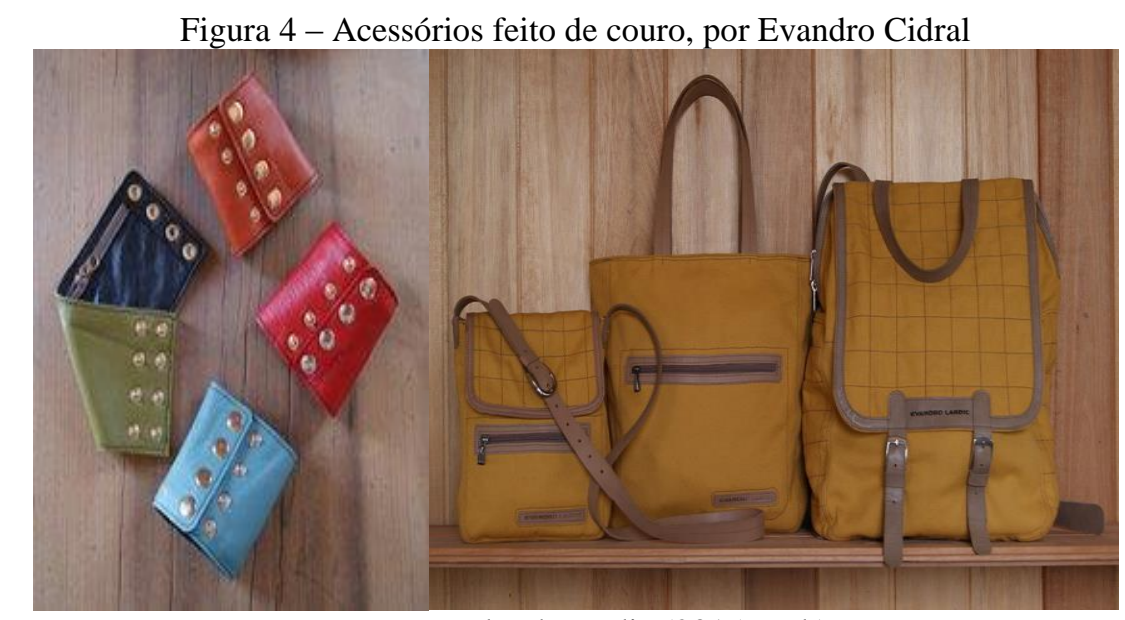

Fonte: Facebook Lardic (2015, web)

A empresa de acessórios Rust Miner tem na sua essência o upcycling. Os materiais utilizados basicamente são retirados de ferros-velhos, oficinas ou adquiridos em lojas de ferragens. Para a confecção dos acessórios da figura 5, foram utilizadas partes de correntes de bicicleta, agregados com cordão de ouro velho e pingente de árvore respectivamente.

Figura 5 - Acessórios feitos com corrente de bicicleta

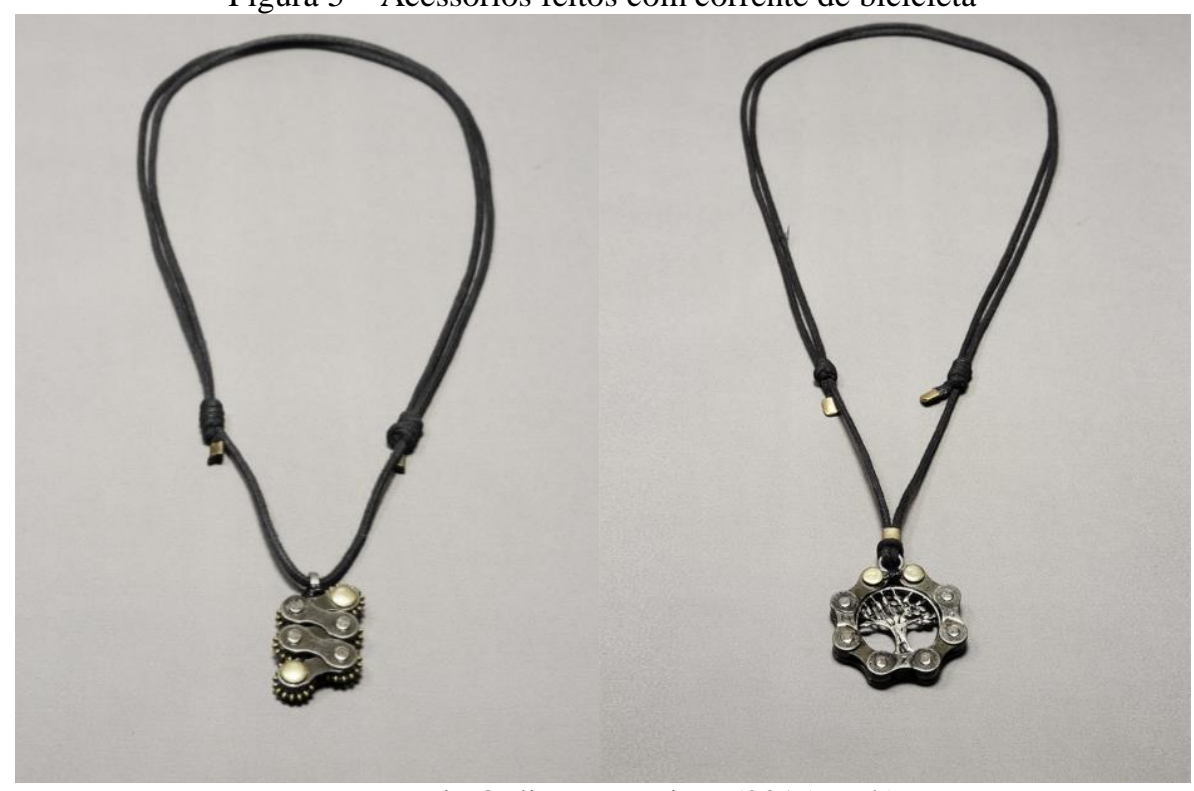

Fonte: Loja Online Rustminer (2015, web)

Os principais pontos de partida da criação de peças com enfoque na ressignificação de materiais foram, além da redução de resíduos gerados por outras empresas/pessoas, a necessidade de diminuir a obsolescência programada e o desafio de criar peças originais. 


\section{plural| $^{\text {GA }}$}

Os materiais utilizados são os mais diversos e inusitados, tendo em comum o fato de que seriam descartados, sejam em lixões, incineradores, ferros-velhos ou até mesmo em locais específicos para descarte, excluindo a possibilidade de serem reutilizados com a intenção de torná-los um novo produto com características inovadoras.

De acordo com os pesquisados, a seleção dos materiais é bastante minuciosa, pois a mesma não pode gerar desperdícios ou resíduos desnecessários, para que esses descartes não voltem para o lixo sem serem utilizados de maneira consciente. A figura 6 mostra a seleção dos materiais realizada pelo designer da Rust Miner em um ferro-velho na cidade de Jaraguá do Sul.

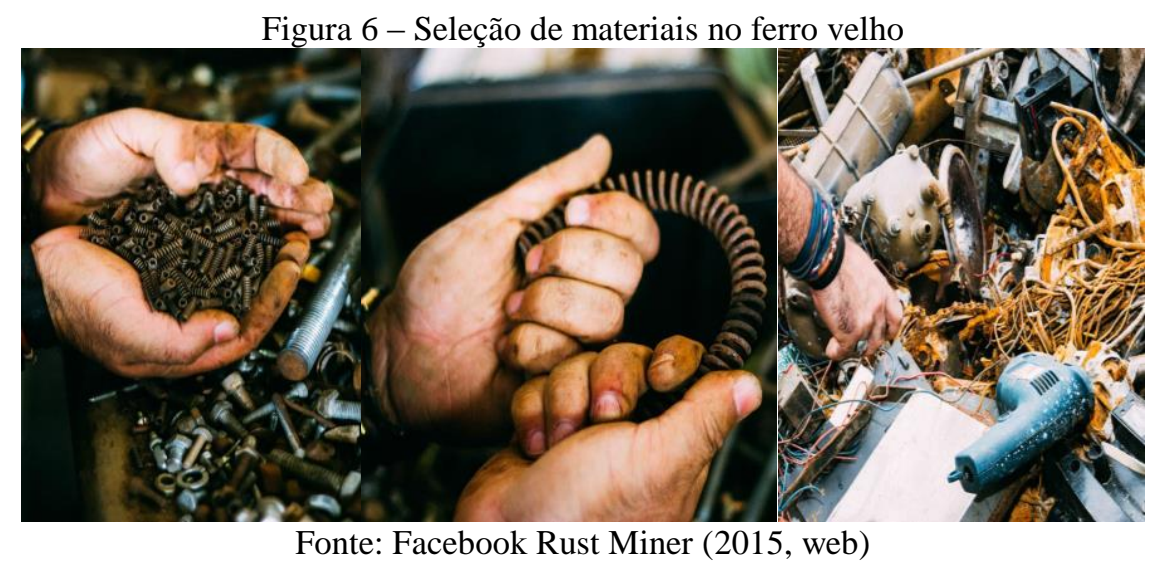

Ao analisar os materiais mais utilizados pelos arranjos produtivos nos locais pesquisados, chegou-se a conclusão que apesar de terem processos e produtos diferentes uns dos outros, as escolhas de cada empreendedor são bastante semelhantes em termo de matériaprima, como pode ser visto no gráfico a seguir.

Gráfico 2 - Matérias primas utilizadas

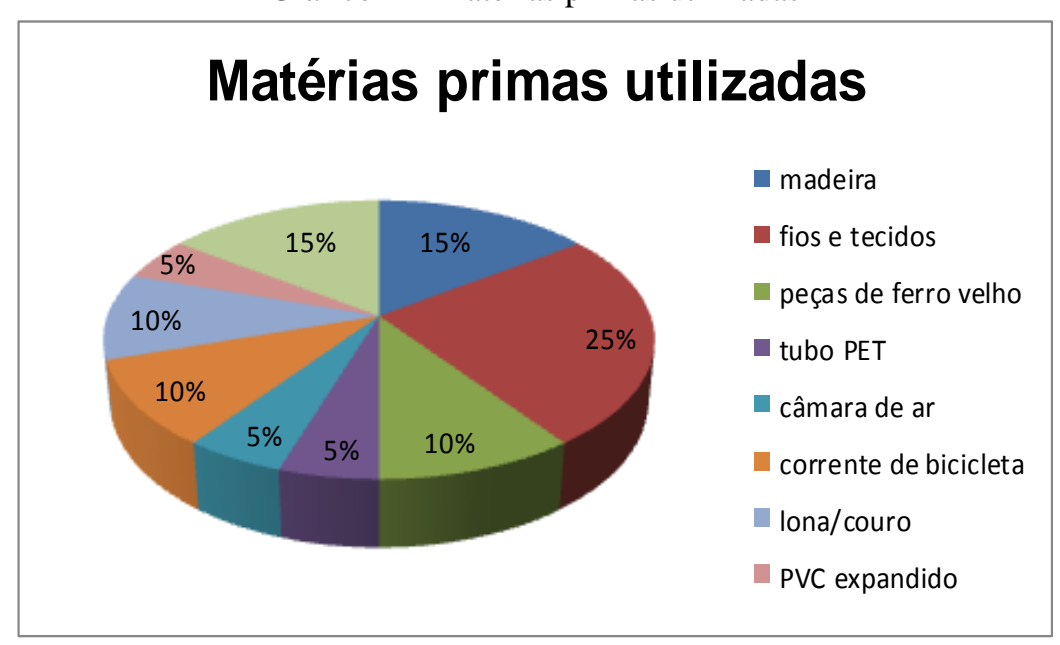

Fonte: A autora (2015) 


\section{GAMPI
plural ${ }^{15}$}

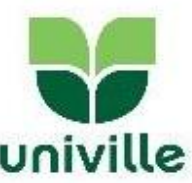

A obtenção dos materiais/resíduos acontece principalmente de duas formas: por meio de doações ou através do garimpo em locais de descarte. Em algumas situações específicas os materiais são comprados e utilizados em conjunto com os demais adquiridos.

Os entrevistados contam que as empresas, ao saberem de seu ramo de atividade, os procuram para realizar parcerias, a fim de destinarem seus resíduos para a criação de novas peças. Esta troca é benéfica para todos os envolvidos, pois a economia neste processo torna o custo de produção mais baixo e a quantidade de resíduos destinados a aterros/incinerações é reduzida, assim como o impacto sobre o meio ambiente.

Mas os benefícios vão muito além. Alguns dos colaboradores da pesquisa expõem que a grande diferença está na propagação do conceito de reuso, pois na área, há certa evangelização referente ao tema, onde as ações, parcerias, workshops e convites para eventos, palestras entre outros, incentivam o desenvolvimento criativo e influenciam diversas marcas a aderirem ao reaproveitamento de materiais descartados, abrindo espaço para um novo nicho de consumidores da marca.

Os "consumidores conscientes" percebem e valorizam o trabalho de empresas que se preocupam com o conceito sustentável. Cada vez mais as pessoas se identificam com os produtos, buscam pelo inusitado, diferente, principalmente se tiver o caráter de "feito a mão" e com valor sustentável.

\section{Conclusão}

Os parâmetros encontrados no decorrer da pesquisa, evidenciaram as mudanças no comportamento dos empreendedores e dos consumidores, perante a crescente preocupação com questões ambientais, comprovando que o design sustentável tem cada vez mais influência na cadeia produtiva das empresas neste segmento.

A problemática desta pesquisa envolvia levantar os tipos de iniciativas de upcycling e suas cadeias produtivas, a fim de identificar quais eram os principais resíduos descartados utilizados no âmbito do design. Após o estudo e análise sobre assuntos abordados e a pesquisa de campo realizada junto às iniciativas de upcycling, constatou-se que os benefícios da ressignificação de materiais pelos empreendimentos pesquisados, estão presentes no valor agregado do produto final e na evangelização que esta prática promove neste segmento.

Nesta concepção, o diferencial apresentado nos artefatos confeccionados com materiais descartados, está na propagação do conceito de reuso e na responsabilidade socioambiental que o empreendedor agrega à sua cadeia produtiva. $O$ desafio está, principalmente, na transformação de forma criativa do material que chegou ao fim de sua vida útil prevista, bem como na redução do impacto que este material causará no ambiente após o seu descarte.

Conclui-se que o conceito de sustentabilidade e upcycling ganham cada vez mais destaque na produção dos artefatos e, também vem obtendo aceitação dos consumidores ao perceber as intenções por trás dos produtos criados, assim como, valorizando a exclusividade.

\section{Referências Bibliográficas}

BUAINAIN, A. M. Agricultura Familiar, Agroecologia e Desenvolvimento Sustentável: questões para debate. Brasília: IICA, 2006. 


\section{GAMPI plural 45}

FERREIRA NETO, A. Desenvolvimento comunitário. Rio de Janeiro: Bloch, 1987.

McDONOUGH, William; BRAUNGART, Michael. Cradle to cradle: remaking the way we make things. USA: North Point Press, 2002.

NAIME, Roberto. Gestão de resíduos sólidos: uma abordagem prática. Novo Hamburgo: Feevale, 2005.

SEBRAE. Serviço Brasileiro de Apoio às Micro e Pequenas Empresas. Disponível em: <http://www.sebrae.com.br/sites/PortalSebrae/>. Acesso em: 21 jun. 2015. 